\title{
THE ASSOCIATION BETWEEN CHILDREN'S SEX AND THEIR MOTHERS' OCCUPATION TO CHILDREN'S BODY MASS INDEX
}

\section{Dessie Wanda*1, Novy Helena Chatarina Daulima $^{2}$, Prihatini Dini Novitasari ${ }^{3}$}

1. Department of Pediatric Nursing, Faculty of Nursing, Universitas Indonesia

2. Department of Psychiatric Nursing, Faculty of Nursing, Universitas Indonesia

3. Faculty of Nursing, Universitas Indonesia

\section{Article Information}

Received: 3 May 2021

Revised: 15 September 2021

Accepted: 6 November 2021

\section{*Corresponding Author}

Dessie Wanda

dessie@ui.ac.id

\section{DOI}

10.20884/1.jks.2021.16.3.1695

\begin{abstract}
Issues related to double-burden malnutrition such as undernutrition and obesity problems in children are of great importance. This study aims to identify the relationship between mothers' culture, feeding practices, and other factors with their children's body mass index (BMI). This is a cross-sectional study that involved 219 mother-child dyads whose children were studying at public elementary schools in DKI Jakarta. The sample was selected by cluster random sampling. Univariate analysis was then used to describe the children's and their parents' characteristics. The bivariate analysis was then conducted to describe the correlation between the children's and parents' characteristics and obesity. The findings showed that mothers' culture and feeding practices were not significantly correlated to their children's BMI. However, there were several factors significantly associated with the children's BMI, namely, sex ( $p=0.009 ; \mathrm{Cl} 95 \%)$ and mothers' occupation $(p=0.026$; $\mathrm{Cl} 95 \%$ ). Girls are likely to have a higher BMI and mothers who work as entrepreneurs are likely to have children with higher BMI. Therefore, nurses should provide optimal education related to the prevention of malnutrition, including obesity in children.
\end{abstract}

Keywords: Children; gender; mother's occupation; obesity

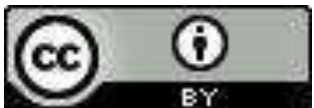

ISSN : 1907-6637

e-ISSN : 2579-9320

\section{INTRODUCTION}

Indonesia is currently facing the double burden of malnutrition in children. It is a condition where some children would suffer from undernutrition (based on weight-for-height), while others would suffer from overnutrition (based on weight-for-height) or is overweight and obese (based on BMl-for-age). An individual is categorized as overweight based on the result from the measurement of BMI-for-age, that is, $>1.0-<2.0$. Meanwhile, obesity is indicated by the result of $>2.0 \mathrm{SD}$. According to Basic Health Research in 2013, children aged 5-12 years were more frequently found to be overweight, compared to children aged 13-18 years. The highest prevalence of overweight individuals by province was in Jakarta (30.1\%), while the lowest was in East Nusa Tenggara (8.7\%) (Kementerian Kesehatan Republik Indonesia, 2013). Both overweight and obesity occur due to several risk factors. According to Ferreira and Marques-vidal (2008) and Sartika (2011), these factors include the children's level of knowledge, family history of obesity, low and high birth weight, exercise habits and physical activity, as well as control of food intake. In this case, controlling the food intake is not only done by children, but also by parents, especially mothers. Therefore, mothers' perception towards their children's nutritional status plays an important role in determining whether they restrict their children to eat or encourage them to keep eating. When mothers think that their children are underweight, they will try to push and force their children to eat in accordance with the family culture and without controlling the children's nutritional status through BMI (Novitasari \& Wanda, 2020; Quah et al., 2018; Webber, Hill, Cooke, Carnell, \& Wardle, 2010). This feeding practice is considered to cause obesity as it encourages children to eat while placing no limitation on their weight. This would affect their children's nutrient intake and would lead to lack of control regarding fat and snack consumption. Thus, such a condition shows how crucial mothers' feeding practice is in causing obesity in children (Rodgers et al., 2013). 
Unfortunately, obesity and overweight as indicated by the BMI score also predisposes the mothers' perception towards their children's condition in relation to overweight or obesity, and this might lead to other problems (Do et al., 2017; Quah et al., 2019). Overweight and obesity in children might lead to problems at the next stage of the children's life, such as problems related to their physical health and self-concept (Do et al., 2017) which further influence their confidence regarding their body image (Shin \& Shin, 2008). A study conducted by Tatangelo et al. (2016) found that children under the age of 6 year could experience dissatisfaction with their body. Girls are more likely to experience dissatisfaction with their body compared to boys (Peralta, Marques, Sarmento, \& Costa, 2017). Parents seem to play an important role in a child's dissatisfaction with their body, such as through limiting the food their child is allowed to consume because their child is overweight or obese (Quah et al., 2019). In Indonesia, not many studies have aimed to identify the association between the mothers' feeding practices and the incidence of obesity in children. Most studies have focused on the characteristics of the children themselves.

Therefore, this study was conducted to identify the relationship between children's and parents' characteristics to obesity in elementary school children. This paper will present the result of the first stage of a bigger study, which is the result from a quantitative approach. The following stage will be the qualitative result which focuses on obese children's self-concept.

\section{METHOD}

Study design

This was a quantitative study with a cross-sectional approach, therefore the independent and dependent variables were only measured one time simultaneously (Sastroasmoro \& Ismael, 2014). The independent variable was obesity, and the dependent variables were the children's characteristics (including age, sex, eating frequency, breakfast habit, means of transportation, and phone ownership) and parents' characteristics (age, parents' occupation, and mothers' feeding practices).

\section{Sample}

The respondents of this study were 219 mother-child dyads who met the inclusion criteria, namely, the child was a student at a public elementary school in DKI Jakarta and the mother was able to read and write. Meanwhile, the exclusion criterion was elementary students who were absent during the data collection period. The sampling technique used was cluster random sampling. Two public elementary schools were chosen randomly from each part of DKI Jakarta as the cluster. In total, we collected data from ten public elementary schools. Then, the students were randomly selected using a website, random.org, based on their attendance list number.

\section{Data collection}

The data related to obesity were collected using an IMT/U instrument in a WHO application called Anthroplus, particularly the anthropometric calculator. The children's and parents' characteristics were measured using questionnaires. The mothers' feeding practice was assessed using the child feeding questionnaire (CFQ) and child eating behavior questionnaire (CEBQ) that were developed by Birch et al. (2001). The CFQ consists of 15 questions about restriction, pressure to eat, and children's eating supervision, while the CEBQ consists of 35 questions which describes the mothers' perception towards their children's eating habits. These questionnaires have been translated using the back translation process and have been tested for its validity and reliability with the Cronbach alpha value of 0.7 by Cerdasari et al. (2017).

During the data collection process, the children's' height and weight were measured to determine their BMI score and to identify whether the child is obese or not. Then, the questionnaires for mothers were sent through the students, and the completed questionnaires would be submitted on the following day to their teachers.

\section{Data analysis}

The data analysis was conducted by univariate and bivariate analysis. The bivariate analysis was conducted to measure the correlation between the related variables (Notoatmodjo, 2010). In this study, the univariate analysis of the variables was presented by frequency and percentage of proportion. Meanwhile, the data to measure the correlation between demographic characteristics and obesity were done using the categorical scale, therefore the statistical tests used were the Chi Square test and the contingency coefficient.

\section{Ethical consideration}

This study has been approved by the Research Ethics Committee, Faculty of Nursing, Universitas Indonesia with the number: SK-217/UN2.F12.D1.2.1/ETIK.FIK.2019.

\section{RESULTS}

\section{Description of Respondent Characteristics}

The respondents in this study were mother-child dyads studying in elementary schools in Jakarta. The mean age of the children was 11.7 years with an age range of $9-14$ years and most of the children were female (52.1\%). Other characteristics such as eating frequency, breakfast intensity, means of transportation, and phone ownership are presented in Table 1. According to Table 1, most of the children sampled eat three times a day, rarely eat breakfast, walk to their school, and have their own mobile phone.

Table 1. Distribution of children's characteristics $(n=219)$

\begin{tabular}{lcc}
\hline Characteristics & Frequency (f) & Percentage (\%) \\
\hline Eating frequency & 4 & 1.8 \\
1 & 58 & 26.5 \\
2 & 139 & 63.5 \\
3 & 18 & 8.2 \\
$>3$ & & \\
\hline Breakfast habit & 6 & 2.7 \\
Never & 89 & 40.6 \\
Rarely & 60 & 27.4 \\
Frequently & 64 & 29.2 \\
Always & & \\
\hline Means of & & 44.3 \\
transportation & 97 & 6.4 \\
On foot & 14 & 2.3 \\
Motorcycle taxi & 5 & 47 \\
Public & & \\
transportation & 103 & 73.1 \\
Other means & & 26.9 \\
\hline Phone ownership & 160 & \\
Yes & 59 & \\
No & &
\end{tabular}

The mean age of the mothers involved in this study was 40.99 years with an age range of 21-71 years. The distribution of parents' occupation can be seen in Table 2. Most of the mothers were housewives and most of the fathers worked as private employees. 


\begin{tabular}{lcc}
\multicolumn{3}{c}{ Table 2. Distribution of parents' occupation (n=219) } \\
\hline $\begin{array}{l}\text { Parents } \\
\text { characteristics }\end{array}$ & $\begin{array}{c}\text { Frequency } \\
\text { (f) }\end{array}$ & $\begin{array}{c}\text { Percentage } \\
\text { (\%) }\end{array}$ \\
\hline Mother's occupation & & \\
Housewife & 167 & 76.3 \\
Civil servant & 1 & 0.5 \\
Private employee & 30 & 13.7 \\
Entrepreneur & 21 & 9.6 \\
\hline Father's occupation & & \\
Unemployed & 14 & 6.4 \\
Civil servant & 6 & 2.7 \\
Private employee & 127 & 58 \\
Entrepreneur & 72 & 32.9
\end{tabular}

\section{Mothers' Feeding Practice}

Mothers' feeding practice was described by the mothers' perception towards their children's food acceptance and refusal. Food acceptance is indicated by the children's response to eating, which includes excessive emotional eating, enjoyment of eating, and desire to drink. The mothers' perception of food refusal is indicated by a feeling of fullness, slow eating, lack of emotion during eating, and fussy eating Furthermore, mothers' feeding practice was also described by their control during the eating process. The descriptions of mothers' feeding practices are presented in Table 3.

Table 3. Mothers' feeding practice in Jakarta, 2019 $(\mathrm{n}=219)$

\begin{tabular}{lcc}
\hline Culture & Frequency (f) & Percentage (\%) \\
\hline Perception of child's food acceptance & \\
Low & 170 & 77.6 \\
High & 49 & 22.4 \\
\hline Perception of child's food refusal & \\
Low & 137 & 62.6 \\
High & 82 & 37.4 \\
\hline Control during eating process & \\
\hline
\end{tabular}

\begin{tabular}{lcc}
\hline Low Control & 168 & 76.7 \\
High Control & 51 & 23.3 \\
\hline
\end{tabular}

From Table 3, the mothers' perception of their children's food acceptance remained low (77.6\%) and the perception of children's food refusal was low (62.6\%) as well. Meanwhile, in terms of feeding practice, most of the mothers had low control in their children's eating process $(76.7 \%)$.

\section{Body Mass Index (BMI) Description}

The description of the children's BMI is presented in Table 4.

Table 4. Children's BMI in Jakarta, 2019 ( $n=219)$

\begin{tabular}{lcc}
\hline Children characteristics & $\begin{array}{c}\text { Frequency } \\
(\mathbf{f})\end{array}$ & $\begin{array}{c}\text { Percentage } \\
(\%)\end{array}$ \\
\hline BMI & & \\
Extremely underweight & 15 & 6.8 \\
Underweight & 20 & 9.1 \\
Normal & 123 & 56.2 \\
Overweight & 31 & 14.2 \\
Obese & 30 & 13.7 \\
\hline
\end{tabular}

From Table 4, based on the BMI scores, more than half of the children $(56.2 \%)$ were of normal weight and $13.7 \%$ of the children were obese.

\section{Correlation between Respondents' Characteristics and Children's BMI}

The correlation between children's and parents' characteristics and children's' obesity was analyzed and only two variables had a significant relationship with obesity, which were the children's sex ( $p$ value $=0.009$ ) and mothers' occupation ( $p$ value $=0.026$ ). The results of the statistical test for this significance are presented in Table 5. Other variables did not show any significant relationship, where the score ranged from 0.186 to 0.769 and the $r$ value ranged from 0.087 to 0.074 .

\begin{tabular}{|c|c|c|c|c|c|c|c|}
\hline $\begin{array}{l}\text { Respondent } \\
\text { characteristics }\end{array}$ & $\begin{array}{c}\text { Extremely } \\
\text { underweight }\end{array}$ & Underweight & Normal & Overweight & Obese & $p$ value & $\mathbf{R}$ \\
\hline \multicolumn{8}{|l|}{ Sex } \\
\hline Female & 1 & 11 & 69 & 16 & 17 & 0.009 & 13.514 \\
\hline Male & 14 & 9 & 54 & 15 & 13 & & \\
\hline \multicolumn{8}{|l|}{ Mother's occupation } \\
\hline Housewife & 13 & 18 & 94 & 24 & 18 & 0.026 & 0.147 \\
\hline Civil servant & 0 & 0 & 0 & 0 & 1 & & \\
\hline Private employee & 1 & 1 & 17 & 3 & 8 & & \\
\hline Entrepreneur & 1 & 1 & 12 & 4 & 3 & & \\
\hline
\end{tabular}

\section{DISCUSSION}

The findings showed that most of the respondents were female. This phenomenon is not only found in this study, as most students in similar recent studies were female. In this study, children's sex has a significant correlation with the children's BMI, where the direction of the relationship is negative. It can also be concluded that female respondents showed higher BMI than male respondents. However, this correlation is categorized as weak. Nevertheless, these results are in line with Fossou et al. (2020) who found a significant correlation with BMI. Furthermore, Srdic et al. (2012) stated that women's BMI are higher than men. In addition, Shriver et al. (2015) also found that girls are more likely to experience being overweight than boys.

In terms of age, most of the girl students sampled are in the early adolescent period. Aliss et al. (2020) stated that girls in the early adolescent stage are more likely to suffer from obesity. In addition, girls tend to be more reluctant to do physical activities and instead spend more time watching TV or playing games, this makes them prone to obesity (Aliss et al., 2020). This was not in line with Sampasa-Kanyinga et al. (2020) who stated that boys are more likely to suffer from obesity. Pham et al. (2020) even stated that the prevalence of boys suffering from overweight and obesity are two times higher than girls during elementary school.

The more time students spend on social media, the less time they have to do other physical activities, and this might lead to the increase of obesity prevalence in children (SampasaKanyinga et al., 2020). However, if they can partake in more physical activities, including activities at school, they could improve their bodily functions and their BMI will remain 
normal (Allen, Telford, Richard, Telford, \& Olive, 2019; Greguol, Gobbi, \& Carraro, 2014).

Furthermore, this study has also identified the correlation between mothers' occupation and children's BMI. In this study, most of the mothers were housewives. Based on the bivariate analysis, mothers' occupation has a significant correlation to their children's BMI. The direction was positive, where mothers who work as entrepreneurs are likely to have a higher prevalence of having children with higher BMI. However, the correlation is weak. This might be because mothers that work as entrepreneurs have less time compared to housewife mothers to perform feeding practices responsively. Novitasari and Wanda (2020) also found that most mothers were less responsive when feeding their children. In addition, Quah et al. (2018) revealed a significant correlation between mothers' feeding practice and children's BMI. Housewife mothers tend to have more time to encourage their children to eat or control their child's eating frequency.

This study also found that most of the children did not have breakfast but still managed to eat three times a day. According to the literature, girls who are used to having breakfast at home showed a lower prevalence of obesity compared to boys (Pham et al., 2020). Children who are used to eating healthy food tend to have a normal BMI, but children who frequently eat fast food tend to be overweight (You et al., 2021). Furthermore, previous studies have found that eating frequency is also correlated to obesity, where children who have regular meal schedules are less likely to be obese (Beckers, Karssen, Vink, Burk, \& Larsen, 2021; Vollmer, Adamsons, Gorin, Foster, \& Mobley, 2015). Mothers who regularly schedule mealtimes, restrict, monitor, and encourage their children to eat will find that their children are more willing to eat together with the family. Therefore, their children's diet quality will be guaranteed (Mou, Jansen, Raat, Nguyen, \& Voortman, 2021). However, in this study, breakfast habits and eating frequency do not have a significant correlation to children's obesity.

The limitation of this study was related to the selection of the children involved in this study. Due to the random sampling technique, we could not involve the same number of obese and non-obese children.

From these findings, girls are more likely to have a higher BMI. Moreover, mothers who work as an entrepreneur and only have a limited time to manage their children's meals are more likely to have children with higher BMls. Therefore, as health professionals, nurses should take part as an educator and case manager and collaborate with other health professionals. Based on this study, it is suggested that nurses provide education for mothers in integrated health centers (posyandu) or during other events to control their children's anthropometrics regularly and bring awareness to mothers to pay more attention to their children's nutrient intake.

Nutrient intake is not only about providing food, but it is also about responsive feeding and taking more time, especially for working mothers, to pay attention to their child's nutrition. As a case manager, when finding obesity or undernutrition cases, nurses can encourage mothers to consult with a nutritionist or nutritionist doctor and check their child's growth and development to ensure that their children are growing and developing well.

\section{CONCLUSION AND RECOMMENDATION}

This study revealed that children's sex and mother's occupation have a significant correlation to their children's $\mathrm{BMI}$, where the children's sex showed a negative correlation and the mother's occupation showed a positive but weak correlation. Therefore, girls are more likely to have higher BMI and mothers who work as entrepreneurs are more likely to have children with higher BMI. Nurses are therefore expected to provide education for parents related to responsive feeding and obesity prevention in children.

\section{ACKNOWLEDGMENT}

The authors would like to express their gratitude to the Faculty of Nursing, Universitas Indonesia, for their financial support and all individuals involved in this study.

\section{REFERENCES}

Aliss, E. M., Sutaih, R. H., Kamfar, H. Z., Alagha, A. E., \& Marzouki, Z. M. (2020). Physical activity pattern and its relationship with overweight and obesity in Saudi children. International Journal of Pediatrics and Adolescent Medicine, 3-7. https://doi.org/10.1016/j. ijpam.2020.03.007

Allen, C. P., Telford, R. M., Richard, Telford, D., \& Olive, L. S. (2019). Sport, physical activity and physical education experiences: Associations with functional body image in children. Psychology of Sport \& Exercise, 45, 1-7. https://doi.org/10.1016/j.psych sport.2019.101572

Beckers, D., Karssen, L. T., Vink, J. M., Burk, W. J., \& Larsen, J. K. (2021). Food parenting practices and children's weight outcomes: A systematic review of prospective studies. Appetite, 158, 1-15. https://doi.org/10.1016/ j.appet.2020.105010

Birch, L. L., Fisher, J. O., Grimm-thomas, K., Markey, C. N., Sawyer, R., \& Johnson, S. L. (2001). Confirmatory factor analysis of the Child Feeding Questionnaire: a measure of parental attitudes, beliefs and practices about child feeding and obesity proneness. Appetite, 201-210. https://doi.org/10.1006/appe.2001.0398

Cerdasari, C., Helmyati, S., \& Julia, M. (2017). Tekanan untuk makan dengan kejadian picky eater pada anak usia 23 tahun. Jurnal Gizi Klinik Indonesia, 13(4), 170-178.

Do, L. M., Larsson, V., Tran, T. K., Nguyen, H. T., Ascher, H., \& Ericksson, B. (2017). Vietnamese mother's conceptions of childhood overweight: Findings from a qualitative study. Global Health Action, 9716(February), 0-11. https://doi.org/10.3402/gha.v9. 30215

Ferreira, R. J., \& Marques-vidal, P. M. (2008). Prevalence and determinants of obesity in children in Public Schools of Sintra, Portugal. Obesity, 16(2), 497-500. https://doi.org/10.1038/oby.2007.74

Fossou, A. F., Bitty, M. L. A., Coulibaly, T. J., Batai, N. F., Toure, M. F., \& Zahe, K. Y. A. S. (2020). Prevalence of obesity in children enrolled in private and public primary schools. Clinical Nutrition ESPEN, 1-6. https://doi.org/10.1016/j.clnesp.2020.10.006

Gaspar, M. J. M., Amaral, T. F., Oliveira, B. M. P. M., \& Borges, N. (2011). Protective effect of physical activity on dissatisfaction with body image in children-A crosssectional study. Psychology of Sport \& Exercise, 12(5), 563-569. https://doi.org/10.1016/j.psychsport. 2011.05 .004 
Greguol, M., Gobbi, E., \& Carraro, A. (2014). Physical activity practice, body image and visual impairment: A comparison between Brazilian and Italian children and adolescents. Research in Developmental Disabilities, 35, 21-26. https://doi.org/10.1016/j.ridd.2013.10.020

Horodynski, M. A., Brophy-herb, H. E., Martoccio, T. L., Contreras, D., Peterson, K., Shattuck, M., Senehi, N., Favreau, Z., Miller, A. L., Sturza, J., Kaciroti, N., \& Lumeng, J. C. (2018). Familial psychosocial risk classes and preschooler body mass index: The moderating effect of caregiver feeding style. Appetite, 123, 216-224. https://doi.org/10.1016/j.appet.2017. 12.025

Jongenelis, M. I., Byrne, S. M., \& Pettigrew, S. (2014). Selfobjectification, body image disturbance, and eating disorder symptoms in young Australian children. Body Image, 11(3), 290-302. https://doi.org/10.1016/j.body im.2014.04.002

Kantanista, A., Osinski, W., Borowiec, J., Tomczak, M., \& Król-zielinska, M. (2015). Body image, BMI, and physical activity in girls and boys aged $14-16$ years. Body Image, 15, 40-43. https://doi.org/10.1016/j. bodyim.2015.05.001

Kementerian Kesehatan Republik Indonesia. (2013). Penyajian Pokok-Pokok Hasil Riset Kesehatan Dasar 2013. Jakarta: Litbangkes Kemenkes RI.

Min, J., Yan, A. F., Wang, V. H. C., \& Wang, Y. (2017). Obesity, body image, and its impact on children's eating and exercise behaviors in China: A nationwide longitudinal study. Preventive Medicine, 1-25. https://doi.org/10.1016/j.ypmed.2017.10.024

Mou, Y., Jansen, P. W., Raat, H., Nguyen, A. N., \& Voortman, T. (2021). Associations of family feeding and mealtime practices with children's overall diet quality: Results from a prospective population-based cohort. Appetite, 160, 1-8. https://doi.org/10.1016/j.appet.2020.1050 83

Notoatmodjo, S. (2010). Metodologi Penelitian Kesehatan. Jakarta: Rineka Cipta.

Novitasari, P. D., \& Wanda, D. (2020). Maternal feeding practice and its relationship with stunting in children. Pediatric Reports, 12. https://doi.org/10.4081/pr.2020. 8698

Oktaviani, M. A., \& Notobroto, H. B. (2014). Perbandingan tingkat normalitas distribusi metode KolmogorovSmirnov, Lilliefors, Shapiro-Wilk, dan SkewnessKurtosis. Jurnal Biometrika Dan Kependudukan, 3(2), 127-135.

Peralta, M., Marques, A., Sarmento, H., \& Costa, F. C. Da. (2017). Effects of obesity on perception of ability and perception of body image in Portuguese children and adolescents. Journal of Human Sport and Exercise, 11(3), 367-375. https://doi.org/10.14198/jhse.2016.1 13.05

Pham, N. K., Sepehri, A., Le, T. M., \& Tran, V. T. (2020). Correlates of body mass index among primary school children in Ho Chi Minh City, Vietnam. Public Health, 181 , 65-72. https://doi.org/10.1016/j.puhe.2019.1 2.007

Quah, P. L., Ng, J. C., Fries, L. R., Chan, M. J., Aris, I. M., Lee, Y. S., Yap, F., Godfrey, K. M., Chong, Y., Shek, L. P., Tan, K. H., Forde, C. G., \& Chong, M. F. F.
(2019). Longitudinal analysis between maternal feeding practices and body mass index (BMI): A study in Asian Singaporean Preschoolers. Frontiers in Nutrition, 6(April), 1-13. https://doi.org/10.3389/fnut.2 019.00032

Quah, P. L., Syuhada, G., Fries, L. R., Chan, M. J., Lim, H. X., Toh, Y., Sugianto, R., Aris, I. M., Lee, Y. S., Yap, F., Godfrey, M., Gluckman, P. D., Chong, Y.-S., Shek, L. P., Tan, K. H., Forde, C. G., \& Chong, M. F. F. (2018). Maternal feeding practices in relation to dietary intakes and BMI in 5 year-olds in a multi-ethnic Asian population. PLOS One, September, 1-16. https://doi.org/https://doi.org/10.1371/journal.pone.02 03045

Rodgers, R. F., Paxton, S. J., Massey, R., Campbell, K. J., Wertheim, E. H., Skouteris, H., \& Gibbons, K. (2013). Maternal feeding practices predict weight gain and obesogenic eating behaviors in young children: A prospective study. International Journal of Behavioral Nutrition and Physical Activity, 10(24), 1-10. https://doi.org/10.1186/1479-5868-10-24

Sampasa-Kanyinga, H., Colman, I., Goldfield, G. S., Hamilton, H. A., \& Chaput, J. (2020). Sex differences in the relationship between social media use, short sleep duration, and body mass index among adolescents. Sleep Health, 1-8. https://doi.org/10. 1016/j.sleh.2020.01.017

Sartika, R. A. D. (2011). Faktor Risiko Obesitas pada Anak 515 Tahun di Indonesia. Makara Kesehatan, 15(1), 3743.

Sastroasmoro, S., \& Ismael, S. (2014). Dasar-Dasar Metodologi Penelitian Klinis (Edisi 5). Jakarta: Sagung Seto.

Shin, N. Y., \& Shin, M. S. (2008). Body dissatisfaction, selfesteem, and depression in obese Korean children. Journal of Pediatric, 152, 502-506. https://doi. org/ 10.1016/j.jpeds.2007.09.020

Shriver, L. H., Hubbs-Tait, L., Harrist, A. W., Topham, G., \& Page, M. (2015). Child gender and weight status moderate the relation of maternal feeding practices to body esteem in 1st grade children. Appetite, 1-8. https://doi.org/10.1016/j.appet.2015.01.017

Srdic, B., Obradovic, B., Dimitric, G., \& Stoki, E. (2012). Relationship between body mass index and body fat in children-Age and gender differences. Obesity Research \& Clinical Practice, 6, 167-173. https://doi.org/10.1016/j.orcp.2011.08.153

Tatangelo, G., McCabe, M., Mellor, D., \& Mealey, A. (2016). A systematic review of body dissatisfaction and sociocultural messages related to the body among preschool children. Body Image, 18, 86-95. https://doi.org/10.1016/j.bodyim.2016.06.003

Vollmer, R. L., Adamsons, K., Gorin, A., Foster, J. S., \& Mobley, A. R. (2015). Investigating the relationship of body mass index, diet quality, and physical activity level between fathers and their preschool-aged children. Journal of the Academy of Nutrition and Dietetics, 1-8. https://doi.org/10.1016/j.jand.2014.12. 003

Webber, L., Hill, C., Cooke, L., Carnell, S., \& Wardle, J. (2010). Associations between child weight and maternal feeding styles are mediated by maternal perceptions and concerns. European Journal of 
Clinical Nutrition, 64(3), 259-265. https://doi.org/10. 1038/ejcn.2009.146

You, Y., Zhang, F., Han, J., Liu, R., Li, B., Ding, Z., Zhou, H., \& Zhang, Q. (2021). Breakfast preferences and consumption location among children at a median age of 7 in Shenzhen: Implications for managing overweight and obesity. Appetite, 156, 1-11. https://doi.org/10.1016/j.appet.2020.104851
Zequinão, M. A., de Medeiros, P., do Rosário, H. R. V., Pelegrini, A., Lopes, L., Pereira, B., \& Cardoso, F. L. (2017). Association between body dissatisfaction and bullying in children of socioeconomically vulnerable areas. Porto Biomedical Journal, 2(6), 260-264. https://doi.org/10.1016/j.pbj.2017.04.010 